\title{
Níveis de energia metabolizável mantendo a relação lisina digestível:caloria em rações para suínos machos castrados em terminação ${ }^{1}$
}

\section{Wilkson Oliveira Rezende ${ }^{2}$, Juarez Lopes Donzele ${ }^{3}$, Rita Flávia Miranda de Oliveira ${ }^{3}$, Márvio Lobão Teixeira de Abreu ${ }^{4}$, Aloízio Soares Ferreira ${ }^{3}$, Francisco Carlos de Oliveira Silva ${ }^{5}$, Lourdes Romão Apolônio 6}

\author{
${ }^{1}$ Parte da tese (Mestrado - Zootecnia) do primeiro autor junto à UFV. Projeto apoiado pela AJINOMOTO. \\ 2 Fiscal Federal Agropecuário - SFFA/DFA-MT. \\ ${ }^{3}$ Departamento de Zootecnia da UFV. \\ ${ }^{4}$ Departamento de Zootecnia da UFPI. \\ 5 EPAMIG. \\ ${ }^{6}$ Doutorando em Zootecnia - UFV.
}

\begin{abstract}
RESUMO - Foram utilizados 40 suínos machos castrados, híbridos comerciais com peso inicial de $60,1 \pm 1,3 \mathrm{~kg}$, em um estudo para avaliar os efeitos de diferentes níveis de EM, mantendo-se a relação lisina digestível:caloria sobre o desempenho e as características de carcaça. Foi utilizado o delineamento experimental de blocos ao acaso, com quatro tratamentos, cinco repetições e dois animais por unidade experimental. Os tratamentos corresponderam a quatro níveis de EM (3.100, 3.230, 3.370 e $3.500 \mathrm{kcal} / \mathrm{kg}$ de ração), nos quais foi mantida a relação de 2,41 g de lisina digestível/Mcal de EM. As rações foram fornecidas à vontade até o fim do período experimental, quando os animais atingiram 95,46 $\pm 2,89 \mathrm{~kg}$. Os níveis de energia metabolizável influenciaram o consumo diário de ração, que reduziu linearmente. A conversão alimentar melhorou linearmente com o aumento dos níveis de energia metabolizável. Não houve efeito dos tratamentos sobre o consumo de energia, o ganho de peso diário, a eficiência de utilização da EM para ganho de peso, o rendimento de carcaça, a espessura de toucinho e o rendimento de carne magra. Níveis crescentes de energia metabolizável (3.100 a $3.500 \mathrm{kcal} / \mathrm{kg}$ ), mantendo-se a relação lisina digestível:caloria na ração de suínos machos castrados, promovem melhora na conversão alimentar e redução no consumo de ração, sem alterar os valores do ganho de peso e das características de carcaça.
\end{abstract}

Palavras-chave: carcaça, densidade energética, fase terminação, genótipo

\section{Metabolizable energy levels maintaining digestible lysine:calorie ratio in diets for finishing barrows}

\begin{abstract}
Forty barrows from commercial hybrids averaging initial weight of $60.1 \pm 1.3 \mathrm{~kg}$ were used in a trial to evaluate different ME levels, maintaining the digestible lysine:calorie ratio, on the performance and carcass characteristics. A randomized block experimental design with four treatments, five replicate and two animals per experimental unit was used. The treatments consisted of four ME levels $(3,100,3,230,3,370$, and 3,500 kcal/ $\mathrm{kg}$ ) with 2.41 $\mathrm{g}$ of digestible lysine/Mcal of EM ratio. Animals were fed until the end of the experimental period, when the animals reached $95.46 \pm 2.89 \mathrm{~kg}$. It was observed linear effect of treatments on feed intake. Feed:gain ratio increased linearly as the ME levels increased. There was no treatment effect on energy efficiency, weight gain, carcass yield, backfat thickness and lean meat yield. It was concluded that increasing ME levels $(3,100$ to $3,500 \mathrm{kcal} / \mathrm{kg}$, maintaining the dietary digestible lysine:calorie ratio of barrows, increase feed:gain ratio and decrease feed intake with no effect on weight gain and carcass characteristics.
\end{abstract}

Key Words: carcass, energy density, finishing phase, genotype

\section{Introdução}

O conteúdo energético das rações é um dos fatores nutricionais mais relevantes para o desempenho de suínos na fase de terminação. Em geral, a energia é o componente nutricional que mais onera a alimentação, pois a maior parte da ração é constituída por alimentos energéticos. Por isso, a busca pela eficiência na nutrição energética dos suínos, aliando ganhos biológicos e econômicos, tem sido contínua.

Os suínos, especialmente na fase de terminação, tendem a alterar o consumo de ração, procurando ajustá-lo aos níveis de energia da dieta. Quanto mais elevado o nível de energia, menor o consumo voluntário. Portanto, a utilização de rações com alta densidade energética na fase de terminação torna 
o consumo voluntário dos animais reduzido e tem sido associado, também, à melhora na eficiência alimentar.

Como o nível de energia de uma ração tem efeito significativo sobre o consumo de ração pelos animais, é desejável que as exigências nutricionais sejam expressas em relação ao conteúdo energético das rações, especialmente as exigências protéicas, considerando o seu perfil de aminoácidos. A adição de lipídios ou a utilização de qualquer alimento de alto valor energético visando ao aumento do conteúdo energético da ração requer a correção dos valores protéicos proporcionalmente, a fim de se evitar desbalanço entre o consumo de energia e de proteína e, conseqüentemente, alteração da partição da energia depositada como gordura ou proteína na carcaça (Usry \& Boyd, 2001).

Apesar de os genótipos modernos responderem melhor ao aumento no consumo de energia, os efeitos de rações com alto nível de energia, com níveis protéicos balanceados, sobre o desempenho e as características de carcaça são pouco conhecidos. A possível vantagem deste manejo nutricional para animais em terminação é pouco relatada, em especial para suínos de alto potencial genético para deposição de carne magra na carcaça.

Na prática, a intensidade das respostas de desempenho de crescimento e de composição corporal (qualidade de carcaça) em termos de energia da ração é fundamental para se estabelecerem estratégias de alimentação adequadas para cada situação.

Assim, este estudo foi conduzido para avaliar os efeitos dos níveis de energia metabolizável da ração, mantendo-se constante a relação lisina digestível:caloria, sobre o desempenho e as características de carcaça de suínos, machos castrados, de alto potencial genético para deposição de carne magra na carcaça, em crescimento.

\section{Material e Métodos}

O experimento foi conduzido na granja de suínos da Empresa de Pesquisa Agropecuária de Minas Gerais (EPAMIG), localizada na Fazenda Experimental do Vale do Piranga, em Oratórios - MG.

Foram utilizados 40 suínos machos castrados, híbridos comerciais, com peso inicial de 60,1 $\pm 1,3 \mathrm{~kg}$, distribuídos em delineamento experimental de blocos ao acaso, com quatro tratamentos $(3.100,3.230,3.370$ e $3.500 \mathrm{kcal}$ de energia metabolizável $/ \mathrm{kg}$ de ração), cinco repetições e dois animais por unidade experimental.

Os animais foram alojados em baias providas de comedouro semi-automático e bebedouros tipo chupeta, localizadas em galpão de alvenaria, com piso de concreto e cobertura de telha de amianto. A limpeza das baias foi realizada diariamente com raspagens dos dejetos. A temperatura do ar foi registrada diariamente por meio de termômetros de máxima e de mínima, colocados em uma baia vazia no interior do galpão.

Para a determinação do ganho de peso diário, os animais foram pesados no início e no final do período experimental, quando atingiram $95,46 \pm 2,89 \mathrm{~kg}$. As rações fornecidas e as sobras de ração foram pesadas semanalmente para posterior determinação do consumo de ração e de energia metabolizável e da conversão alimentar.

As rações experimentais (Tabela 1) foram formuladas à base de milho e farelo de soja, acrescidas de óleo de soja ou farelo de trigo para proporcionar os níveis de energia metabolizável desejados, sendo suplementadas com núcleo de minerais e vitaminas, atendendo ou excedendo as recomendações do NRC (1998), uma vez que foi mantida constante a relação lisina digestível:energia metabolizável.

As rações experimentais foram formuladas com quatro níveis de energia metabolizável (3.100, 3.230, 3.370 e $3.500 \mathrm{kcal} / \mathrm{kg}$ de ração), mantendo-se a relação energia metabolizável:lisina digestível $(2,41 \mathrm{~g}$ de lisina digestível por Mcal de energia metabolizável), resultando em níveis de lisina digestível de 0,$747 ; 0,779 ; 0,811$ e $0,844 \%$, respectivamente.

O aumento dos níveis de energia metabolizável e de lisina digestível foi obtido mediante modificações na proporção de óleo de soja e farelo de soja. Os níveis dos aminoácidos essenciais foram estimados a fim de garantir que suas concentrações em relação à lisina ficassem, no mínimo, igual àquela da proteína ideal, preconizado por Fuller (1996). As rações e a água foram fornecidas aos animais à vontade.

Ao final do período experimental, após jejum de 18 horas, os animais foram pesados e encaminhados para um frigorífico comercial, onde foram abatidos por atordoamento elétrico, seguido de sangramento, sendo depilados por escalda e lança-chamas e depois eviscerados.

As carcaças, sem a cabeça e os pés, foram pesadas e avaliadas quanto ao rendimento de carne magra e a espessura de toucinho, por meio de aparelho de tipificação de carcaça (pistola GP-4 Henessy).

As variáveis de desempenho e as características de carcaça foram analisadas por meio do programa computacional SAEG (Sistemas de Análises Estatísticas e Genéticas), desenvolvido pela Universidade Federal de Viçosa (2000), versão 8.0, utilizando-se os procedimentos para análises de variância e regressão. 
Tabela 1 - Composições centesimal e calculada das rações experimentais

Table 1 - Ingredient and calculated compositions of the experimental diets

Ingrediente $(\%)$

Ingredient
Nível de EM (kcal/kg de ração)

ME levels ( $\mathrm{kcal} / \mathrm{kg}$ of diet)

\begin{tabular}{|c|c|c|c|c|}
\hline & & & & \\
\hline & 3.100 & 3.230 & 3.370 & 3.500 \\
\hline Milho (Corn) & 67,434 & 67,885 & 63,436 & 58,903 \\
\hline Farelo de soja (Soybean meal) & 24,074 & 26,175 & 27,836 & 29,544 \\
\hline Farelo de trigo (Oat meal) & 4,382 & - & - & - \\
\hline Óleo de soja (Soybean oil) & - & 1,83 & 4,618 & 7,427 \\
\hline DL-metionina (99\%) (DL-methionine) & - & - & - & 0,016 \\
\hline Núcleo mineral vitamínico ${ }^{1}$ (Vitamin and mineral mix) & 4,000 & 4,000 & 4,000 & 4,000 \\
\hline Antioxidante (Antioxidant) & 0,010 & 0,010 & 0,010 & 0,010 \\
\hline Promotor de crescimento (Growth promoter) & 0,100 & 0,100 & 0,100 & 0,100 \\
\hline
\end{tabular}

Composição calculada ${ }^{2}$

Calculated composition

\begin{tabular}{|c|c|c|c|c|}
\hline $\mathrm{EM}(M E)(\mathrm{kcal} / \mathrm{kg})$ & 3.100 & 3.233 & 3.366 & 3.500 \\
\hline Proteína bruta (Crude protein) (\%) & 17,47 & 17,74 & 18,11 & 18,51 \\
\hline Lisina digestível (Digestible lysine) (\%) & 0,75 & 0,78 & 0,81 & 0,84 \\
\hline Met + cist digestível (Digestible met + cys) $(\%)$ & 0,52 & 0,52 & 0,53 & 0,55 \\
\hline Treonina digestível (Digestible threonine) (\%) & 0,55 & 0,57 & 0,59 & 0,60 \\
\hline Triptofano digestível (Digestible tryptophan) (\%) & 0,180 & 0,18 & 0,19 & 0,20 \\
\hline Cálcio (Calcium) (\%) & 0,65 & 0,65 & 0,65 & 0,65 \\
\hline Fósforo disponível (Avaliable phosphorus) & 0,32 & 0,32 & 0,32 & 0,32 \\
\hline
\end{tabular}

1 Contém por quilograma do produto (Content by kg of product): Ácido fólico (Folic acid), $9 \mathrm{mg}$; Ácido pantotênico (Pantothenic acid), $177 \mathrm{mg}$; Antioxidante (Antioxidant), 1.030 mg; Biotina (Biotin), 1,4 mg; Ca, 142 g; Co, 3,7 mg; Cu, 2.216 mg; Fe, 1.932 mg; F (máx.), 238 mg; P, 54 g (solubilidade ácido cítrico 90\%) (Solubility in citric acid, 90\%); I, 29,5 mg; Mn, 936 mg; Niacina (Niacin), $462 \mathrm{mg}$; Piridoxina (Pyridoxine), 13,3 mg; Promotor de crescimento (Growth promoter), $1235 \mathrm{mg}$

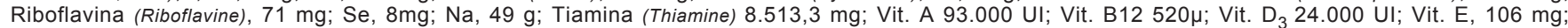
Vit. $\mathrm{K}_{3}, 53 \mathrm{mg} ; \mathrm{Zn} 2.049 \mathrm{mg}$.

2 Composição calculada com base nos valores contidos em Rostagno et al. (2000) (According to Rostagno et al., 2000 tables).

\section{Resultados e Discussão}

As temperaturas mínimas e máximas registradas durante o período experimental, foram, respectivamente, $13,61 \pm 3,46$ e $26,23 \pm 3,12^{\circ} \mathrm{C}$.

Os valores de desempenho, consumo diário de EM e de lisina digestível e eficiência de utilização da EM para ganho de peso dos suínos machos castrados dos 60 aos $95 \mathrm{~kg}$, em função dos níveis de EM da ração, são apresentados na Tabela 2.

Observou-se efeito $(\mathrm{P}<0,01)$ do nível de EM da ração sobre o consumo diário de ração (CDR), que reduziu de forma linear (Figura 1). Este resultado corrobora aqueles obtidos por Brumm \& Miller (1996) e Smith et al. (1999), que observaram redução linear do CDR de suínos em fase de terminação em função do aumento da densidade energética da ração. Resultado semelhante foi também obtido por Ettle et al. (2003), que constataram menor CDR para os animais que receberam a ração com maior nível de $\mathrm{EM}(3.350 \mathrm{kcal} / \mathrm{kg})$ em relação aos que receberam as rações com menor nível $(3.110 \mathrm{kcal} / \mathrm{kg})$.

A redução no CDR parece estar relacionada a um ajuste dos animais aos tratamentos na tentativa de satisfazer sua demanda de energia, uma vez que não houve efeito dos níveis de $\mathrm{EM}(\mathrm{P}>0,10)$ sobre o consumo diário de $\mathrm{EM}(\mathrm{CEM})$. Diferentes autores, entre eles Lopez-Bote et al. (1997) e De la Llatta et al. (2001), confirmaram com seus resultados que,

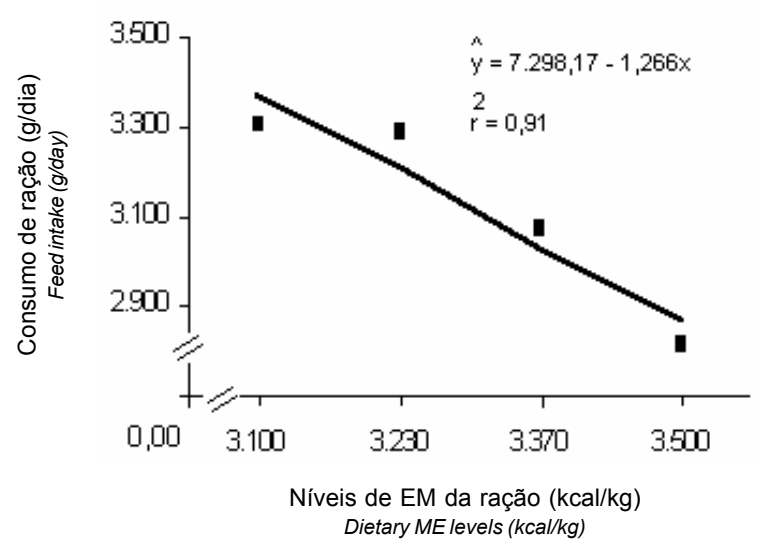

Figura 1 - Consumo de ração (g/dia) de suínos em terminação segundo os níveis de EM da ração.

Figure 1 - Feed intake (g/day) of finishing barrows as affected by the dietary ME levels. 
Tabela 2 - Desempenho, consumo diário de EM (CEM), consumo diário de lisina digestível e eficiência de utilização de EM para ganho de peso (EUG) de suínos machos castrados dos 60 aos $95 \mathrm{~kg}$, em função do nível de EM da ração

Table 2 - Performance, daily ME intake (MEI), daily digestible lysine intake, and efficiency of ME utilization for weight gain (GUE) of barrows from 60 to $95 \mathrm{~kg}$ as affected by the dietary ME level

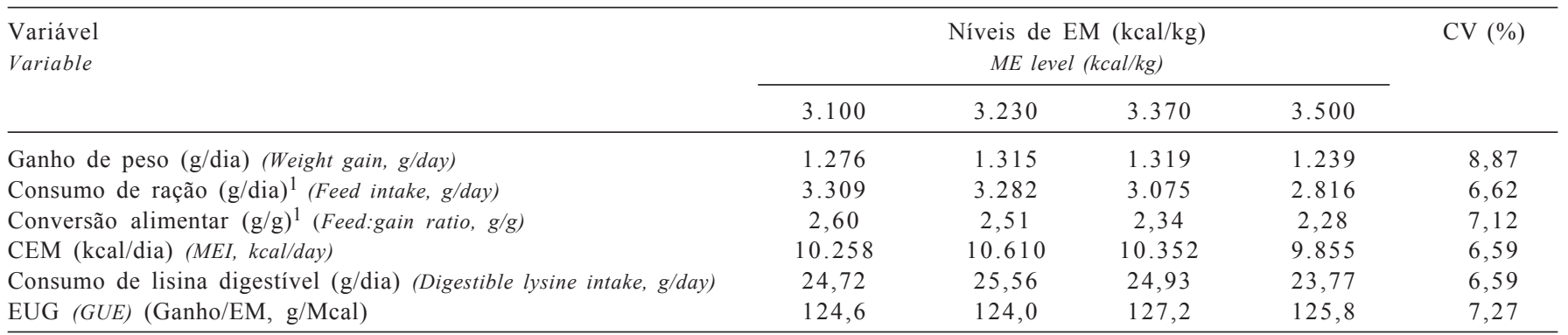

${ }^{1}$ Efeito linear $(P<0,01)$ (Linear effect, $\left.P<.01\right)$.

quando a relação lisina:energia da ração é mantida, os suínos compensam a baixa densidade energética da ração, aumentando a ingestão de alimento, até que determinado nível de consumo de energia seja atingido.

Como a relação entre o nível de lisina digestível e de EM das rações foi mantida constante $(2,41)$, o consumo de lisina digestível, da mesma forma que o EM, não variou $(P>0,05)$ entre os tratamentos.

Não se observou efeito $(\mathrm{P}>0,05)$ dos níveis de EM da ração sobre o ganho de peso diário (GPD) dos animais. Resultados similares foram obtidos por Eggert et al. (1997) e Ettle et al. (2003), que também não observaram variação no GPD de suínos em terminação em função do aumento dos níveis de EM da ração, quando mantida a relação lisina:energia. Em contrapartida, Levasseur et al. (1998), avaliando o aumento da densidade energética da ração para suínos desde a fase de crescimento até a terminação, observaram aumento do GPD dos animais.

Os resultados divergentes quanto aos efeitos dos níveis de EM sobre o GPD podem, em parte, estar relacionados às diferenças entre as faixas de peso avaliadas. Estudando os efeitos do aumento da densidade energética, mantendo a relação lisina:energia, sobre o desempenho de suínos em crescimento e terminação em três fases distintas (39 aos $59 \mathrm{~kg}, 59$ aos $93 \mathrm{~kg}$ e 93 aos $120 \mathrm{~kg}$ ), De La Llatta et al. (2001) observaram aumento no GPD dos animais entre 39 e $59 \mathrm{~kg}$ e nenhuma variação significativa no ganho de peso dos animais com peso acima de $59 \mathrm{~kg}$. O aumento no GPD na faixa de peso entre 39 e $59 \mathrm{~kg}$ foi suficiente para aumentar significativamente o ganho de peso de todo o período (crescimento-terminação), dos 39 aos $120 \mathrm{~kg}$.

Segundo Bikker et al. (1995), suínos selecionados para alta deposição de carne magra na carcaça encontram-se, até os $45 \mathrm{~kg}$, em fase dependente de energia, ou seja, a deposição de proteína parece ser limitada pela baixa capacidade

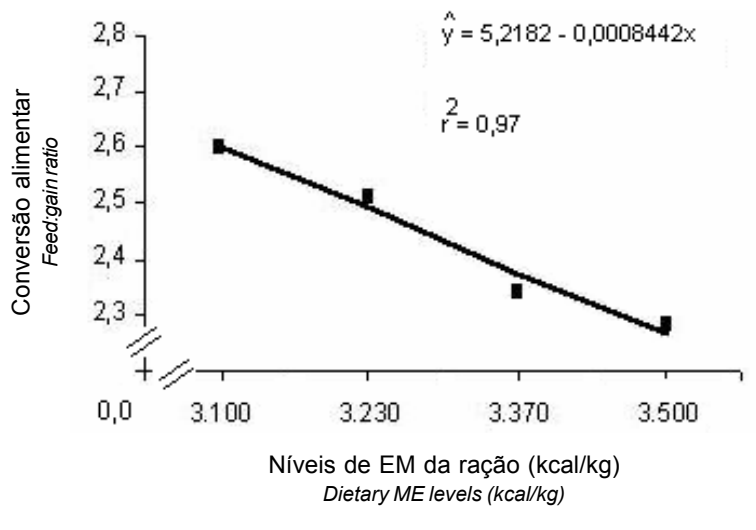

Figura 2 - Conversão alimentar de suínos em terminação segundo os níveis de EM da ração.

Figure 2 - Feed:gain ratio of finishing barrows as affected by the dietary ME levels.

de consumo de alimento desses animais. Assim, o uso de rações de alta densidade de energia nesta fase tem sido relacionado ao aumento do consumo de energia e, conseqüentemente, ao aumento no GPD.

Com relação à conversão alimentar, constatou-se melhora $(\mathrm{P}<0,01)$ linear em razão dos níveis de EM da ração (Figura 2). O resultado observado neste estudo é similar ao obtido por diversos autores (Stein et al., 1996; Lopez-Bote et al., 1997; Smith et al., 1999; Myer et al., 1992).

Entre os dados de desempenho dos animais normalmente avaliados nos diferentes experimentos, a resposta positiva da $\mathrm{CA}$ ao aumento da densidade energética da ração tem sido a mais consistente. A manutenção da relação lisina:energia permite ao animal adequada ingestão de aminoácidos e energia com consumo menor de rações com maior nível de energia.

Embora a CA tenha melhorado de forma linear com o aumento dos níveis de EM da ração, não se observou efeito $(\mathrm{P}>0,05)$ dos tratamentos sobre a eficiência de utilização da 
EM para ganho de peso (EUG). Este resultado é semelhante aos encontrados por Stein et al. (1996) e Levasseur et al. (1998), que também não observaram variação na EUG.

Apesar da coerência entre os dados de EUG nesses trabalhos, o valor médio de 125,4 g/Mcal de EM, encontrado neste estudo foi bem superior aos valores médios de 97,9 e 76,9 g/Mcal de EM obtidos por Smith et al. (1999) para suínos dos 44,5 aos 104,3 kg e dos 72,6 aos 104,3 kg, respectivamente; aos de 106,5 e 106,6 g/Mcal encontrados por Quiniou et al. (1996) e Ettle et al. (2003), para machos castrados dos 45 aos 100 e dos 56 aos $110 \mathrm{~kg}$, respectivamente; e ao de 100,2 g/Mcal de EM encontrado por De la Llata et al. (2001), que trabalharam com unidades experimentais mistas de suínos machos castrados e fêmeas dos 59 aos $93 \mathrm{~kg}$.

A diferença na capacidade de crescimento e deposição de tecido magro dos animais utilizados nos diferentes estudos, pode ter contribuído para a variação dos resultados de EUG observados. Segundo Schinkel \& Einstein (1995), genótipos modernos atingem máxima deposição de proteína em pesos mais elevados, o que justifica os altos valores de GPD e, conseqüentemente, a alta eficiência de utilização de energia para ganho desses animais na fase de terminação.

O fato de o ganho de peso diário e a EUG não terem sido influenciados pelos tratamentos estaria indicando manutenção da composição do ganho de peso, com semelhante relação entre as deposições de proteína e gordura corporal dos animais entre os tratamentos.

Os dados das características de carcaça avaliadas (rendimento de carcaça, espessura de toucinho e rendimento de carne magra) de suínos machos castrados dos 60 aos $95 \mathrm{~kg}$, em função dos níveis de energia da ração, encontram-se na Tabela 3 .

Não se constatou efeito $(\mathrm{P}>0,05)$ dos níveis de $\mathrm{EM}$ sobre o rendimento de carcaça, o rendimento de carne magra e a espessura de toucinho. Resultados similares foram obtidos por De La Llata et al. (2001), que não observaram efeito da inclusão de gorduras em rações de suínos, mantendo-se a relação lisina:energia, sobre a espessura de toucinho, porcentagem de carne magra e o rendimento de carcaça de animais abatidos aos $120 \mathrm{~kg}$.

Resultados semelhantes foram encontrados também por Myer et al. (1992) e Williams et al. (1994), que não observaram efeito do aumento da densidade energética da ração, pela adição de gordura, sobre a espessura de toucinho e a área de olho-de-lombo. Ettle et al. (2003) também não observaram efeito dos níveis de EM da ração sobre os rendimentos de carne magra e de carcaça dos animais abatidos aos $110 \mathrm{~kg}$.

Os resultados de espessura de toucinho obtidos não confirmam o relato feito por Pettigrew \& Moser (1991), com base em revisão de literatura, de que a adição de lipídios à ração para suínos em crescimento-terminação geralmente aumenta o conteúdo de gordura na carcaça.

Com relação aos dados de rendimento de carcaça, estes resultados contrastam com aqueles obtidos por Smith et al. (1999), Stein et al. (1996) e Lopez-Bote et al. (1997), que, avaliando níveis crescentes de EM, mantendo a relação lisina:caloria para suínos em crescimento e terminação, observaram aumento no rendimento de carcaça. A diferença nos resultados obtidos pode ser decorrente do menor período experimental avaliado nesse estudo (somente a terminação), o que reduziu o tempo para a resposta fisiológica do animal, e/ou da variação na composição das rações avaliadas quanto ao nível de fibra, que nesse estudo ficou substancialmente abaixo dos níveis utilizados por esses autores.

De acordo com Just (1982), o aumento da inclusão de alimentos fibrosos para reduzir o nível de energia da ração, por aumentar o peso do trato digestivo, resulta em diminuição do rendimento de carcaça dos suínos.

Os resultados de desempenho e de características de carcaça obtidos nesse estudo corroboram a observação de Usry \& Boyd (2001) de que o balanceamento da proteína ideal em relação à energia, mantendo-se constante a relação lisina digestível:caloria, tem sido eficaz para melhorar o desempenho de suínos de genótipos modernos na fase de terminação alimentados com rações ricas em energia, sem o comprometimento da qualidade de carcaça.

Tabela 3 - Rendimento de carcaça, espessura de toucinho e rendimento de carne magra na carcaça de suínos machos castrados dos 60 aos $95 \mathrm{~kg}$, em função do nível de EM da ração

Table 3 - Carcass yield, backfat thickness and carcass lean yield of barrows from 60 to $95 \mathrm{~kg}$ as affected by the dietary ME levels

\begin{tabular}{|c|c|c|c|c|c|}
\hline \multirow[t]{2}{*}{$\begin{array}{l}\text { Variável } \\
\text { Variable }\end{array}$} & \multicolumn{4}{|c|}{$\begin{array}{c}\text { Níveis de EM ( } \mathrm{kcal} / \mathrm{kg} \text { de ração) } \\
\text { ME level ( } \mathrm{kcal} / \mathrm{kg} \text { of diet) }\end{array}$} & \multirow[t]{2}{*}{ CV $(\%)$} \\
\hline & 3.100 & 3.233 & 3.366 & 3.500 & \\
\hline Rendimento de carcaça (\%) (Carcass yield, \%) & 71,64 & 70,05 & 71,60 & 71,40 & 2,532 \\
\hline Espessura de toucinho (mm) (Backfat thickness, $\mathrm{mm}$ ) & 14,4 & 13,78 & 13,78 & 13,64 & 3,464 \\
\hline Rendimento de carne magra (\%) (Lean yield, \%) & 56,22 & 56,16 & 55,98 & 56,23 & 16,817 \\
\hline
\end{tabular}




\section{Conclusões}

O aumento do nível de energia metabolizável de 3.100 para $3.500 \mathrm{kcal} / \mathrm{kg}$ de ração, mantendo a relação lisina digestível:caloria na ração de suínos machos castrados em terminação, promove melhora na conversão alimentar e redução no consumo de ração sem alterar o ganho de peso e as características de carcaça.

\section{Literatura Citada}

BIKKER, P.; KARABINAS, V.; VERSTEGEN, M.W.A. et al. Protein and lipid accretion in body components of growing gilts (20 to 45 kilograms) as affected by energy intake. Journal of Animal Science, v.73, n.8, p.2355-2363, 1995.

BRUMM, M.C.; MILLER, P.S. Response of pigs to space allocation and diets varying in nutrient density. Journal of Animal Science, v.74, n.11, p.2730-2737, 1996.

DE LA LLATA, M.; DRITZ, S.S.; TOKACH, M.D. et al. Effects of dietary fat on growth performance and carcass characteristics of growing-finishing pigs reared in a commercial environment. Journal of Animal Science, v.79, n.10, p.2643-2650, 2001.

EGGERT, J.M.; FARRAND, E.J.; SCHINCKEL, A.P. et al. [1997]. The effects of dietary fat and lysine on pig growth, pork quality and carcass composition. Purdue University. Swine Day Report, Disponível em: <http://www.ansc.purdue.edu/ swine/swineday/sday97/psd14-97.htm Acesso em: 05/08/2003.

ETTLE, T.; ROTH-MAIER, D.A.; ROTH, F.X. Effect of apparent ideal digestible lysine to energy ratio on performance of finishing pigs at different dietary metabolizable energy levels. Journal of Animal Physiology and Animal Nutrition, v.87, n.7-8, p.269-279, 2003.

FULLER, M.F. Macronutrient requirements of growing swine. In: SIMPÓSIO INTERNACIONAL SOBRE EXIGÊNCIAS NUTRICIONAIS DE AVES E SUÍNOS, 1996, Viçosa, MG. Anais... Viçosa, MG: Universidade Federal de Viçosa, 1996, p.205-221.

JUST, A. The net energy value of crude fat for growth in pigs. Livestock Production Science, v.9, p.501-509, 1982.

LEVASSEUR, P.; COURBOULAY, V.; MEUNIER-SALAUN, M.C. et al. Influence de la source d'energie et de la concentration énergétique de l'aliment sur le comportament alimentaire, les performances zootechniques et les qualités de carcasse du porc charcutier. Journées Recherche Porcine en France, v.30, p.245-252, 1998.

LOPEZ-BOTE, C.J.; SANZ, M.; ISABEL, B. et al. Effect of dietary lard on performance, fatty acid composition and susceptibility to lipid peroxidation in growing-finishing females and entire male pigs. Canadian Journal of Animal Science, v.77, n.2, p.301-306, 1997.
MYER, R.O.; LAMKEY, J.W.; WALKER, W.R. et al. Performance and carcass characteristics of swine when fed diets containing canola oil and added copper to alter the unsaturated:saturated ratio of pork fat. Journal of Animal Science, v.70, n.5, p.1417-1423, 1992.

NATIONAL RESEARCH COUNCIL - NRC. Nutrient requirements of swine. 10.ed. Washington, D.C.: National Acemy Press, 1998. $189 \mathrm{p}$.

PETTIGREW, J.E.; MOSER, R.L. Fat in swine nutrition. In: MILler, E.R.; UllReY, D.E.; LEWIS, A.J. (Eds.) Swine nutrition. Butterwrth-Heinemann: Stoneham, 1991. p.133-146.

QUINIOU, N.; DOURMAD, J.Y.; NOBLET, J. Effect of energy intake on the performance of different types of pig from 45 to $100 \mathrm{~kg}$ body weight. 1. Protein and lipid deposition. Animal Science, v.63, p.277-288, 1996.

ROSTAGNO, H.S.; ALBINO, L.F.T.; DONZELE, J.L. et al. Composição de alimentos e exigências nutricionais de aves e suínos: tabelas brasileiras. Viçosa, MG: Universidade Federal de Viçosa, 2000. 141p.

SCHINCKEL, A.P.; EINSTEIN, M.E. Concepts of pig growth and composition. In: PURDUE SWINE DAY, 1995, Purdue. Anais... Purdue University, 1995. p.118.

SMITH, J.W.; TOKACH, M.D.; O'QUINN, P.R. et al. Effects of dietary energy density and lysine:calorie ratio on growth performance and characteristics of growing-finishing pigs. Journal of Animal Science, v.77, p.3007-3015, 1999.

STEIN, H.H.; HAHN, J.D.; EASTER, R.A. Effect of decreasing dietary energy concentration in finishing pigs on carcass composition. Journal of Animal Science, v.74 (Suppl.1):65, 1996.

UNIVERSIDADE FEDERAL DE VIÇOSA - UFV. SAEG - Sistema de análises estatísticas e genéticas. Versão 8.0. Viçosa, MG: 2000. (Manual do usuário)

USRY, J.; BOYD, R.D. Realidade da nutrição nos EUA: Sistemas de energia modificada, proporção entre lisina e energia e dietas com altos teores de energia para suínos em crescimento relacionados ao desempenho animal, produção de carne e custos de produção. In: WORKSHOP LATINO-AMERICANO AJINOMOTO BIOlAtina, 1., Foz do Iguaçu. Anais... Foz do Iguaçu: Ajinomoto Biolatina, 2001.p.103-133.

WILLIAMS, N.H.; CLIN, T.R.; SCHINCKEL, A.P. et al. The impact of ractopamine, energy intake, and dietary fat on finisher pig growth performance and carcass merit. Journal of Animal Science, v.72, p.3152-3162, 1994. 